\title{
Potential Molecular Cross Talk Among CCR5 Pathway Predicts Regorafenib Responsiveness in Metastatic Colorectal Cancer Patients
}

\author{
MITSUKUNI SUENAGA ${ }^{1,2,3}$, WU ZHANG ${ }^{1}$, TETSUO MASHIMA ${ }^{4}$, MARTA SCHIRRIPA ${ }^{1}$, \\ SHU CAO ${ }^{5}$, SATOSHI OKAZAKI ${ }^{1}$, MARTIN D. BERGER ${ }^{1}$, YUJI MIYAMOTO ${ }^{1}$, \\ AFSANEH BARZI ${ }^{1}$, TOSHIHARU YAMAGUCHI ${ }^{2}$ and HEINZ-JOSEF LENZ ${ }^{1}$ \\ ${ }^{I}$ Division of Medical Oncology, Norris Comprehensive Cancer Center, \\ Keck School of Medicine, University of Southern California, Los Angeles, CA, U.S.A.; \\ ${ }^{2}$ Gastroenterology Center, Cancer Institute Hospital of Japanese Foundation for Cancer Research, Tokyo, Japan; \\ ${ }^{3}$ Department of Specialized Surgeries, Tokyo Medical and Dental University (TMDU), Tokyo, Japan; \\ ${ }^{4}$ Division of Molecular Biotherapy, Cancer Chemotherapy Center, \\ Japanese Foundation for Cancer Research, Tokyo, Japan; \\ ${ }^{5}$ Department of Preventive Medicine, Norris Comprehensive Cancer Center, \\ Keck School of Medicine, University of Southern California, Los Angeles, CA, U.S.A.
}

\begin{abstract}
Background: Genetic variants in the CCL5/CCR5 pathway have been shown to predict regorafenib efficacy in patients with metastatic colorectal cancer ( $m C R C$ ). This study investigated the biological role of CCL4 and CCL3 gene polymorphisms in patients with refractory $m C R C$ treated using regorafenib. Patients and Methods: We analyzed the genomic DNA extracted from $m C R C$ patients receiving regorafenib. Serum factor levels at baseline, day 21, and progressive disease (PD) were measured using ELISA. Results: Decreased CCL4 levels at day 21 or increased CCL3 levels at PD were associated with better clinical outcomes. In patients with any CCL5 rs2280789 $G$ allele, CCL3 significantly increased between $B L$ and day 21 compared with the A/A variant $(72.7 \%$ vs. $23.1 \%, p=0.006)$, but CCL4 decreased $(31.8 \%$ vs. $69.2 \%, p=0.043)$. Conclusion: Increased CCL3 and decreased CCL4 seen in specific genotypes may serve as potential biomarkers of regorafenib in $m C R C$ patients.
\end{abstract}

This article is freely accessible online.

Correspondence to: Mitsukuni Suenaga, MD, Ph.D., Department of Specialized Surgeries, Tokyo Medical and Dental University (TMDU), 1-5-45 Yushima, Bunkyo-ku, Tokyo 113-8519, Japan. Tel: +81 358035261, Fax: +81 358030138, e-mail: m.suenaga1972@gmail.com

Key Words: CCL3, CCL4, CCL5, CCR5, regorafenib, SNPs, metastatic colorectal cancer.
Regorafenib, an oral multi-kinase inhibitor, confers the benefit of longer survival in patients with refractory metastatic colorectal cancer (mCRC) $(1,2)$. Although in the retrospective exploratory study of the CORRECT trial, circulating DNA was identified as a potential prognostic marker for clinical outcomes (3), there have been few studies to confirm these results. In the previous translational research, baseline serum $\mathrm{C}-\mathrm{C}$ motif chemokine ligand 5 (CCL5) levels and decreased serum vascular endothelial growth factor-A (VEGF-A) levels after initiation of treatment predicted the efficacy of regorafenib in refractory mCRC (4). CCL5 is characterized by late expression after $\mathrm{T}$ cell activation, and it localizes with tumor-infiltrating leukocytes $(5,6)$; it is also known as RANTES (regulated on activation normal $\mathrm{T}$ cell expressed and secreted). The candidate mechanism of action of CCL5/VEGFA signaling is supported by findings from some preclinical studies $(7,8)$. CCL5 can promote endothelial progenitor cell (EPC) migration modulated by its receptor $\mathrm{C}-\mathrm{C}$ motif chemokine receptor 5 (CCR5); CCL5/CCR5 signaling induces VEGF-A production via EPC migration (7). An in vivo study revealed that only CCL5 induced EPC migration in a dosedependent manner, in the presence of $\mathrm{C}-\mathrm{C}$ motif chemokine ligand 3 (CCL3) and 4 (CCL4), CCL5, and C-C motif chemokine receptor 5 (CCR5), whereas CCL3 and CCL4 lacked this activity (8). In another study, mRNA expression of CCL4 and CCL3 were up-regulated in cancer tissues compared to normal tissues, unlike that of CCL5 (9). These findings suggest that CCL5 plays an important role in VEGF-A production among the ligands of CCR5; the potential roles of CCL3 and CCL4 would therefore also be interesting to clarify. 
Table I. Candidate SNPs in CCL3, CCL4, CCL5 and CCR5 genes.

\begin{tabular}{|c|c|c|c|c|c|}
\hline $\begin{array}{l}\text { Genes } \\
\text { rs number }\end{array}$ & Allele location & $\begin{array}{c}\text { Base } \\
\text { exchange }\end{array}$ & $\begin{array}{c}\mathrm{MAF}^{\dagger} \\
(\mathrm{CEU} / \mathrm{JPN})\end{array}$ & $\begin{array}{c}\text { Function of } \\
\text { polymorphism }\end{array}$ & $\begin{array}{l}\text { Forward/Reverse } \\
\text { primer (5'-3') }\end{array}$ \\
\hline CCL3 & Synonymous & $\mathrm{G}>\mathrm{A}$ & $0.31 / 0.31$ & Protein coding, splicing regulation, & F: GCCTTTCCAGGATAGCCTTC \\
\hline rs 1130371 & $\begin{array}{l}\text { Chromosome 17:36089191 } \\
\text { Intron }\end{array}$ & $C>A$ & & $\begin{array}{l}\text { post translation, conserved } \\
\text { Tag SNP }\end{array}$ & $\begin{array}{l}\text { R: CTTTGAGACGAGCAGCCAGT } \\
\text { F: CCGATTCCTTAAACCGTGCT }\end{array}$ \\
\hline $\begin{array}{l}\text { CCL4 } \\
\text { rs1634517 }\end{array}$ & Chromosome 17:36105010 & $\mathrm{C}>\mathrm{A}$ & $0.33 / 0.22$ & Tag SNP & \\
\hline CCL5 & Intron & $A>G$ & $0.11 / 0.31$ & Transcriptional regulation & F: ATCTCCCCAACATGAGTCCA \\
\hline rs2280789 & Chromosome 17:35879999 & & & & R: CCATATGTCCTGTTGTCCTTGA \\
\hline CCL5 & Intron & $\mathrm{A}>\mathrm{T}$ & $0.15 / 0.31$ & Transcriptional regulation & F: TGATATCGGGGTAGGGCATA \\
\hline rs3817655 & Chromosome 17:35872637 & & & & R: GGCGATTAAAATGCACACAA \\
\hline CCR5 & 5' prime UTR & $\mathrm{C}>\mathrm{T}$ & $0.47 / 0.48$ & Transcriptional regulation & F: TGGGATGAGCAGAGAACAAA \\
\hline rs1799988 & Chromosome 3:46370768 & & & & R: GGCGAAAAGAATCAGAGAACA \\
\hline
\end{tabular}

MAF, Minor allele frequency; CEU, Caucasian; JPN, Japanese; F, forward primer; R, reverse primer; Tag SNP, tagging SNP. †In Caucasians and Japanese from the Ensembl Genome Browser: http://uswest.ensembl.org/index.html.

Recently, we reported the results of a unique pharmacogenetic study where the genetic variant in the CCL5/CCR5 pathway was shown to predict the efficacy of regorafenib in metastatic colorectal cancer patients (mCRC) (10). More specifically, CCL5 rs2280789 G allele and CCL5 rs3817655 T allele were associated with longer overall survival (OS) and severe skin toxicity owing to low VEGF-A production via endothelial progenitor cells (EPC). CCL4 rs1634517 C allele and CCL3 rs1130371 $\mathrm{G}$ allele correlated with longer progression-free survival (PFS) and overall survival (OS). However, to deepen the knowledge regarding the network of CCR5 and the associated ligands in cancer treatment, more comprehensive data of the circulating factors are needed.

To investigate the biological role of CCL4 and CCL3 gene polymorphisms, we further checked the circulating protein levels of CCR5 and its ligands CCL3, CCL4, and CCL5; we analyzed the relationship between SNPs and serial serum factor changes during the treatment and studied the correlation among the tested serum factor levels. To this end, the genetic functionality and biological role of CCL4 and CCL3 genotypes were assessed in the CCR5 network in patients with refractory $\mathrm{mCRC}$ treated with regorafenib.

\section{Patients and Methods}

Study design and patients. The original pharmacogenetic study investigated genomic DNA extracted from 208 whole blood and 21 tissues of two independent cohorts comprising patients with refractory, histologically-confirmed mCRC; these included an evaluation cohort of 79 patients treated with regorafenib at the Cancer Institute Hospital in Japan and a validation cohort of 150 patients treated with regorafenib at Azienda OspedalieroUniversitaria Pisana (Pisa, Italy) and Istituto Oncologico Veneto (Padua, Italy) (10). In the current study, we evaluated the clinical impact of serum levels of CCR5 and its ligands-CCL3, CCL4, and CCL5 - in the CCL5/CCR5 pathway in the evaluation cohort and investigated the correlation among the SNPs and all serum factor levels. All patients met the eligibility criteria: history of previous standard chemotherapy including 5-fluorouracil, oxaliplatin, irinotecan, bevacizumab, and cetuximab or panitumumab for $K R A S$ or $R A S$ wild-type; presence of measurable or assessable lesions and signed informed consent. Adverse events were graded according to the Common Terminology Criteria for Adverse Events, version 4.0. Patients received $160 \mathrm{mg}$ of regorafenib (Bayer, Leverkusen, Germany) once daily from day 1 to day 21 every 4 weeks. Doses were adjusted based on adverse events at a physician's discretion, following the manufacturer's recommendations. The study was compliant with the Reporting Recommendations for Tumor Marker Prognostic Studies (REMARK) guidelines. The analyses were approved by the Institutional Review Board of each institute and conducted at the University of Southern California/Norris Comprehensive Cancer Center and in accordance with the Declaration of Helsinki and Good Clinical Practice Guidelines.

Selection of candidate single-nucleotide polymorphisms (SNPs). The candidate SNPs in CCL3, CCL4, CCL5, and CCR5 genes were selected depending on the following criteria: i) biological significance of SNPs according to published literature review; ii) tagging SNPs selected using the HapMap genotype data with $\mathrm{r}^{2}$ threshold $=0.8$ (https://snpinfo.niehs.nih.gov/snpinfo/guide.html) or iii) minor allele frequency with a cut-off of $\geq 10 \%$ in Caucasians and East Asians (in the Ensembl Genome Browser: http://uswest. ensembl.org/index.html). Significance of functionality of SNPs was predicted based on the functional single-nucleotide polymorphism (F-SNP) database (11) (Table I). The SNP data analyzed in our previous study (10) were used in the analysis of the current study to explore their functionality.

DNA extraction and genotyping. In our original study, genomic DNA was extracted from peripheral whole blood or tissue in patients of both cohorts, using the QIAmp Kit (Qiagen, Valencia, CA, USA), according to the manufacturer's protocol (www.qiagen.com). The only exception was formalin-fixed paraffinembedded tissues of 21 patients from the evaluation cohort. The candidate SNPs were tested with polymerase chain reaction (PCR)based direct DNA sequence analysis using the ABI 3100A Capillary 
Genetic Analyzer and Sequencing Scanner v1.0 (Applied Biosystems, Life Technologies, Grand Island, NY, USA). The forward and reverse primers used for amplification of extracted DNA are listed in Table I. For quality control purposes, a randomly selected $10 \%$ of the samples were analyzed by direct DNA sequencing for each SNP, resulting in a genotype concordance rate of $99 \%$ or more. The investigators analyzing the SNPs were blinded to the clinical data.

Analysis of serum factor levels. Blood samples were obtained from 58 Japanese patients enrolled in the evaluation cohort at baseline (BL) before the first dose of regorafenib, at day 21 in the first cycle, and at progressive disease (PD). Separated serum was stored at $80^{\circ} \mathrm{C}$. The levels of serum factors were measured using Quantikine ELISA kits (R\&D Systems). The data regarding VEGF-A and CCL5 were previously reported in the original study (10). In the current study, serum CCL3, CCL4, and CCR5 levels were additionally tested for further analysis of the CCL5/CCR5 signaling network; the relationship between serum factor levels and genotypes was also evaluated. However, the analysis of CCL3, CCL4, and CCR5 was performed in 35 patients, and the other 23 patients were excluded from the analysis owing to the lack of samples.

Statistical analysis. The primary endpoint of the current study was progression-free survival (PFS), and the secondary endpoints were overall survival (OS) and disease control rate (DCR). PFS was defined as the interval between the date of starting treatment and the date of confirmed disease progression or death. The data of patients without disease progression or death were censored at the date of the last follow-up. OS was calculated from the date of starting treatment until the date of death from any cause. In patients who discontinued follow-up, data were censored at the date of the last follow-up. DCR was defined as the proportion of patients who achieved a complete response (CR), partial response (PR), or stable disease (SD) according to the Response Evaluation Criteria in Solid Tumors (RECIST) v1.1. PD was also based on assessment of radiologic images using the RECIST v1.1 and defined as $\geq 20 \%$ increase in the sum of diameters of target lesions taking as reference the smallest sum on this study. The tumor shrinkage (TS) was defined as a reduction of the sum of the longest diameters of target by $0 \%$ or more when compared with BL. The Chi-square test or Wilcoxon test was used to examine the differences in BL patient characteristics between the two cohorts. The allelic distribution of polymorphisms was tested for deviation from the Hardy-Weinberg equilibrium using Fisher's exact test, while linkage disequilibrium among SNPs was assessed using $D^{\prime}$ and $r^{2}$ values, and haplotype frequencies of the genes were inferred using HaploView version 4.2 (http://www.broad.mit.edu/mpg/haploview). Fisher's exact test was applied to examine the associations between SNPs and DCR or toxicity. Kaplan-Meier analysis and the log-rank test were performed to evaluate the association between candidate SNPs and PFS or OS. The BL demographic and clinical characteristics that remained statistically significantly associated with PFS and OS in multivariable analyses were included in the final models to reevaluate the independent effect of candidate SNPs. As the true modes for candidate SNPs were not yet established, the analyses used a codominant, dominant, or recessive genetic model as appropriate. Differences in serum factor levels at any point and those between BL and day 21 or PD were analyzed using Student's unpaired $t$-test for the mean values or the Mann-Whitney $U$-test for
Table II. Baseline patients and tumor characteristics.

\begin{tabular}{|c|c|c|}
\hline \multirow[t]{2}{*}{ Cohort } & \multicolumn{2}{|c|}{ Evaluation cohort $(\mathrm{N}=79)$} \\
\hline & $\mathrm{N}$ & $\%$ \\
\hline \multicolumn{3}{|l|}{ Gender } \\
\hline Male & 37 & 46.8 \\
\hline Female & 42 & 53.2 \\
\hline \multicolumn{3}{|l|}{ Age (year) } \\
\hline Median (range) & \multicolumn{2}{|c|}{$62(34-83)$} \\
\hline$\leq 65$ & 48 & 60.8 \\
\hline$>65$ & 31 & 39.2 \\
\hline \multicolumn{3}{|c|}{ ECOG Performance status } \\
\hline ECOG 0 & 44 & 55.7 \\
\hline ECOG $1-2$ & 35 & 44.3 \\
\hline \multicolumn{3}{|l|}{ Primary tumor site } \\
\hline Right & 23 & 29.1 \\
\hline Left & 56 & 70.9 \\
\hline \multicolumn{3}{|l|}{ Liver metastasis } \\
\hline Yes & 53 & 67.1 \\
\hline No & 26 & 32.9 \\
\hline \multicolumn{3}{|l|}{ Lung metastasis } \\
\hline Yes & 46 & 58.2 \\
\hline No & 33 & 41.8 \\
\hline \multicolumn{3}{|c|}{ Lymph node metastasis } \\
\hline Yes & 40 & 50.6 \\
\hline No & 39 & 49.4 \\
\hline \multicolumn{3}{|c|}{ Peritoneal metastasis } \\
\hline Yes & 20 & 25.3 \\
\hline No & 59 & 74.7 \\
\hline \multicolumn{3}{|c|}{ Number of metastases } \\
\hline$<2$ & 24 & 30.4 \\
\hline$\geq 2$ & 55 & 69.6 \\
\hline \multicolumn{3}{|c|}{ Primary tumor resected } \\
\hline Yes & 69 & 87.3 \\
\hline No & 10 & 12.7 \\
\hline \multicolumn{3}{|l|}{ Adjuvant history } \\
\hline Yes & 26 & 32.9 \\
\hline No & 53 & 67.1 \\
\hline
\end{tabular}

the median values. Spearman's rank correlation coefficient was calculated for correlations among serum factors and Pearson's correlation coefficient was used for data with normal distribution. All analyses were carried out using SAS 9.4 (SAS Institute, Cary, NC, USA). All tests were two-sided at a significance level of 0.05 .

\section{Results}

Patient and tumor BL characteristics. The median follow-up time was 15.3 months and median PFS and OS were 2.0 and 8.7 months, respectively. The BL characteristics are summarized in Table II. Median age was 62 years and 35 out of 79 patients $(44.3 \%)$ had PS 1 or 2 . All candidate SNPs were within the Hardy-Weinberg equilibrium.

Association between serum factor and clinical outcomes. Association between serum factors and clinical outcomes are 
shown in Table III and Table IV. The median serum CCL3 change between BL and day 21 was higher in patients with TS compared to those without TS (13.0 vs. $-4.1 \mathrm{pg} / \mathrm{ml}, p=0.045)$, and the pattern of increased CCL3 levels at PD was associated with longer OS than that of decreased CCL3 levels (12.6 vs. 4.8 months, $p=0.003$ ). In contrast, patients with TS tended to have lower changes in serum CCL4 levels from BL to day 21 $(-13.2 v s .7 .6 \mathrm{pg} / \mathrm{ml}, p=0.054)$ and PD $(-15.4 v s .-2.5 \mathrm{pg} / \mathrm{ml}$, $p=0.064)$ than those without TS. In addition, patients with the pattern of decreased CCL4 levels at day 21 had a trend toward (2.7 vs. 2.0 months, $p=0.09$ ). Concerning CCR5, patients with TS had lower mean changes in serum CCR5 levels between BL and day 21 compared with those without TS ( -0.1 vs. 0.2 $\mathrm{pg} / \mathrm{ml}, p=0.041$ ) (Table III). There were no significant differences in DC and TS in BL serum factor levels, whereas serum CCL3 and CCR5 levels at day 21 were higher in patients with TS compared to those without TS (Table IV).

Correlations among serum factors. Spearman's rank correlation coefficient between different serum factors during treatment are shown in Table V. Moderate correlations were observed in some pairs at day 21 including CCL3-CCL5 and CCL4-CCL5 and at PD including CCL4-CCR5, CCL4VEGF, and CCL5-VEGF. A moderate correlation was only found in a pair of CCL3-CCL5 for changes between BL and day 21. However, there were no significant pairs at BL.

Associations between SNPs and serum factor levels. In our previous study, we demonstrated that the CCL3 rs1130371 $\mathrm{G} / \mathrm{G}$ variant and CCL4 rs $1634517 \mathrm{C} / \mathrm{C}$ variant are associated with better clinical outcome and we analyzed the correlation between SNPs and CCL5 or VEGF (10). Briefly, patients with $C C L 3$ rs $1130371 \mathrm{G} / \mathrm{G}$ variant and CCL4 rs $1634517 \mathrm{C} / \mathrm{C}$ variant tended to have increased CCL5 levels at day 21, whereas those with the CCR 5 rs 1799988 variant mainly had decreased CCL5 levels. In this study, the serum factors CCL3, CCL4 and CCR5 were analyzed for association with SNPs, and the results are shown in Table VI. Patients with the $\mathrm{G} / \mathrm{G}$ variant in $C C L 3 \mathrm{rs} 1130371$ had increased CCL3 levels (median, $9.5 \mathrm{vs} .-4.6 \mathrm{pg} / \mathrm{ml}, p=0.041$ ) at day 21 compared to those with any A allele. In contrast, the CCL4 rs1634517 C/C variant was associated with higher CCR5 changes between $\mathrm{BL}$ and day 21 compared to any A allele in CCLA rs1634517 (median, 0.17 vs. $-0.035, p=0.042$ ) but did not correlate with CCL4 levels. In patients with any CCL5 rs2280789 $\mathrm{G}$ allele, CCL3 tended to increase between BL and day $21(72.7 \%, p=0.006)$, but CCL4 conversely decreased $(31.8 \%, p=0.043)$. Similar results were obtained in CCL5rs3817655. In partial correlation analysis with CCL5 as controlled variable, negative correlation between CCL3 and CCL4 for change between BL and day 21 were observed in the CCL3 $\mathrm{rs} 1130371 \mathrm{G} / \mathrm{G}$ variant $(r=-0.542, p=0.030)$ longer PFS compared to those with increased CCL4 levels

\begin{tabular}{|c|c|c|c|c|c|c|c|}
\hline & & & & & & & \\
\hline 曾 & तु. & $\stackrel{\text { ڤ̊ }}{\stackrel{0}{0}}$ & $\stackrel{\infty}{\stackrel{\infty}{0}}$ & $\stackrel{\infty}{n}$ & 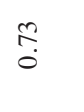 & $\stackrel{\substack{0 \\
\infty}}{\infty}$ & 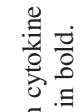 \\
\hline 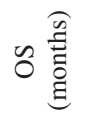 & $\hat{b} \cdot \stackrel{\overbrace{}}{\underline{G}}$ & $\stackrel{\infty}{+} \underset{+}{\stackrel{i}{+}}$ & $\stackrel{\infty}{\sim} \stackrel{m}{\varrho}$ & 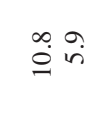 & $\stackrel{3}{0}$ & $\stackrel{\infty}{=} \widehat{b}$ & 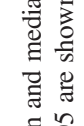 \\
\hline 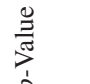 & $\stackrel{\widehat{n}}{0}$ & तે & oे. & $\begin{array}{l}n \\
n \\
0\end{array}$ & $\begin{array}{l}+ \\
\stackrel{0}{0} \\
0\end{array}$ & $\stackrel{\mathbb{N}}{0}$ & $\begin{array}{l}E \\
0\end{array}$ \\
\hline 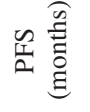 & $\vec{i} \vec{m}$ & भु) & $\grave{i} \stackrel{i}{i}$ & ì & $\vec{i} \stackrel{\vec{i}}{i}$ & $\stackrel{n}{i} \hat{i}$ & 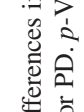 \\
\hline Z & 유 & $\pm \pi$ & is $=$ & $\tilde{\lambda} \pm$ & $\curvearrowleft \approx$ & $\stackrel{-}{\bar{c}}$ & \\
\hline 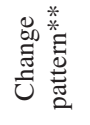 & 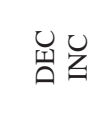 & 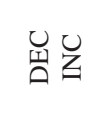 & 峲艺 & 品异 & 剀 & 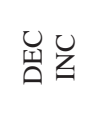 & a \\
\hline 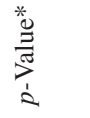 & $\stackrel{f}{\stackrel{8}{0}}$ & $\stackrel{n}{0}$ & 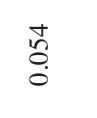 & ț & $\stackrel{\circ}{\circ}$ & $\begin{array}{l}\hat{\infty} \\
0 \\
0\end{array}$ & 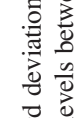 \\
\hline 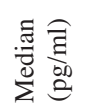 & 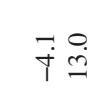 & $\stackrel{\infty}{0} \stackrel{?}{?}$ & $\stackrel{0}{\sim} \underset{0}{1}$ & 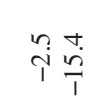 & 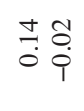 & $\stackrel{0}{0} \stackrel{0}{0}$ & 奇 \\
\hline 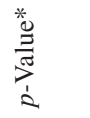 & ஃ̊ & $\stackrel{m}{8}$ & $\hat{0}$ & $\stackrel{1}{\circ}$ & $\stackrel{\bar{J}}{0}$ & $\stackrel{n}{n}$ & 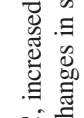 \\
\hline ڤิ & $\stackrel{2}{2} \cdot \vec{r}$ & $\stackrel{+}{\dot{m}} \stackrel{\infty}{\dot{m}}$ & 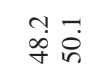 & 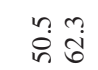 & $\stackrel{m}{0}_{0}^{t}$ & 范苛 & \\
\hline 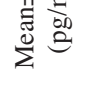 & 节萑 & 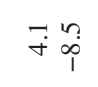 & $\stackrel{\partial}{\dot{1}} \stackrel{m}{\hat{i}}$ & $m_{\infty}^{m} \frac{t}{F}$ & $\stackrel{n}{0}=$ & $\overrightarrow{0} \overrightarrow{0} \dot{0}$ & \\
\hline 7 & $\stackrel{+}{\sim} \bigcirc$ & 호으 & 그 & 긍 & ㄱㅇㅇ & ㄱㅇ & \\
\hline$\tilde{\omega}$ & $z>$ & $z>$ & $z>$ & $z>$ & $z>$ & $z>$ & \\
\hline 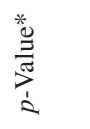 & กี & $\stackrel{t}{\stackrel{t}{0}}$ & $\underset{0}{\stackrel{J}{0}}$ & $\stackrel{n}{m}$ & $\stackrel{?}{0}$ & $\begin{array}{l}\stackrel{0}{\infty} \\
0 \\
0\end{array}$ & 害 \\
\hline 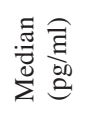 & $\ddot{O} \ddot{m}$ & $\stackrel{i}{i} \stackrel{0}{\circ}$ & $\begin{array}{l}+\infty \\
0 \\
0 \\
\substack{\infty \\
1}\end{array}$ & 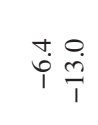 & $\frac{1}{10}$ & : & $\ddot{\bar{\theta}}$ \\
\hline 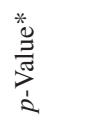 & $\tilde{\sigma}$ & in & $\begin{array}{l}n \\
n \\
0\end{array}$ & \begin{tabular}{l}
0 \\
\multirow{0}{0}{} \\
0
\end{tabular} & $\stackrel{?}{\stackrel{f}{0}}$ & mे & 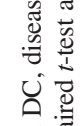 \\
\hline 令 & 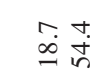 & ஜேं & 享 & $\begin{array}{l}n \\
\text { n? } \\
\text { in }\end{array}$ & m? & t. & \\
\hline$\sum_{\Sigma}^{\overline{5}} \stackrel{\text { bj }}{3}$ & $\begin{array}{l}0 \\
+ \\
\dot{T}\end{array}$ & $\stackrel{+}{+}$ & 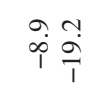 & 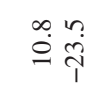 & $\overrightarrow{0}=$ & $\exists \tilde{0}$ & \\
\hline z & $\simeq \stackrel{\infty}{=}$ & $\simeq \stackrel{\infty}{\simeq}$ & $=\infty$ & $=\stackrel{\infty}{=}$ & $\simeq \stackrel{\infty}{=}$ & $\simeq \stackrel{\infty}{-\infty}$ & \\
\hline Ŭ & $z \succ$ & $z>$ & $z>$ & $z>$ & $z>$ & $z>$ & ఏి \\
\hline 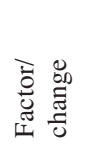 & 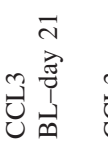 & 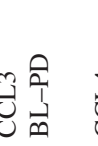 & 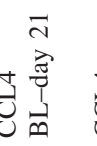 & 苍志 & $\overrightarrow{\vec{N}}$ & 结 & $\vec{\infty}$. \\
\hline
\end{tabular}


Table IV. Serum factor levels and clinical outcomes.

\begin{tabular}{|c|c|c|c|c|c|c|c|c|c|c|c|c|c|c|}
\hline \multirow{3}{*}{$\begin{array}{l}\text { Factor } \\
\text { CCL3 BL }\end{array}$} & \multirow{2}{*}{$\begin{array}{c}\mathrm{DC} \\
\mathrm{N}\end{array}$} & \multirow{2}{*}{$\begin{array}{l}\mathrm{N} \\
17\end{array}$} & \multicolumn{2}{|c|}{$\begin{array}{c}\text { Mean } \pm \text { SD } \\
(\mathrm{pg} / \mathrm{ml})\end{array}$} & \multirow{2}{*}{$\frac{p \text {-Value* }}{0.61}$} & \multirow{2}{*}{$\begin{array}{c}\text { Median } \\
(\mathrm{pg} / \mathrm{ml})\end{array}$} & \multirow{2}{*}{$\begin{array}{c}\text {-Value* } \\
0.82\end{array}$} & \multirow{2}{*}{$\begin{array}{c}\mathrm{TS} \\
\mathrm{N}\end{array}$} & \multirow{2}{*}{$\begin{array}{l}\mathrm{N} \\
24\end{array}$} & \multicolumn{2}{|c|}{$\begin{array}{c}\mathrm{Mean} \pm \mathrm{SD} \\
(\mathrm{pg} / \mathrm{ml})\end{array}$} & \multirow{2}{*}{$\frac{p \text {-Value* }}{0.40}$} & \multirow{2}{*}{$\begin{array}{c}\begin{array}{c}\text { Median } \\
(\mathrm{pg} / \mathrm{ml})\end{array} \\
22.9\end{array}$} & \multirow{2}{*}{$\frac{p \text {-Value* }}{0.99}$} \\
\hline & & & 28.6 & 22.2 & & & & & & 29.3 & 21.9 & & & \\
\hline & $\mathrm{Y}$ & 18 & 35.8 & 53.2 & & 21.8 & & $\mathrm{Y}$ & 10 & 42.7 & 69.3 & & 21.8 & \\
\hline \multirow[t]{2}{*}{ CCL3 day 21} & $\mathrm{~N}$ & 17 & 24.0 & 11.4 & 0.24 & 20.8 & 0.24 & $\mathrm{~N}$ & 24 & 23.2 & 11.6 & 0.007 & 20.8 & 0.009 \\
\hline & $\mathrm{Y}$ & 18 & 29.8 & 16.5 & & 28.4 & & $\mathrm{Y}$ & 10 & 37.3 & 17.2 & & 34.8 & \\
\hline \multirow[t]{2}{*}{ CCL3 PD } & $\mathrm{N}$ & 17 & 33.2 & 37.4 & 0.95 & 19.0 & 0.25 & $\mathrm{~N}$ & 24 & 33.4 & 32.7 & 0.94 & 26.4 & 0.35 \\
\hline & $\mathrm{Y}$ & 18 & 32.6 & 17.7 & & 33.4 & & $\mathrm{Y}$ & 10 & 34.2 & 16.6 & & 28.6 & \\
\hline \multirow[t]{2}{*}{ CCL4 BL } & $\mathrm{N}$ & 17 & 49.7 & 29.2 & 0.30 & 39.4 & 0.96 & $\mathrm{~N}$ & 24 & 50.5 & 35.2 & 0.27 & 39.4 & 0.58 \\
\hline & $\mathrm{Y}$ & 18 & 68.2 & 68.0 & & 41.6 & & $\mathrm{Y}$ & 10 & 81.7 & 81.4 & & 43.8 & \\
\hline \multirow[t]{2}{*}{ CCL4 day 21} & $\mathrm{~N}$ & 17 & 40.8 & 30.6 & 0.59 & 29.3 & 0.95 & $\mathrm{~N}$ & 24 & 45.6 & 44.6 & 0.85 & 32.2 & 0.75 \\
\hline & $\mathrm{Y}$ & 18 & 49.0 & 53.8 & & 32.9 & & $\mathrm{Y}$ & 10 & 42.4 & 45.4 & & 29.9 & \\
\hline \multirow[t]{2}{*}{ CCL4 PD } & $\mathrm{N}$ & 17 & 60.6 & 52.6 & 0.40 & 54.8 & 0.08 & $\mathrm{~N}$ & 24 & 58.8 & 50.8 & 0.39 & 47.0 & 0.092 \\
\hline & $\mathrm{Y}$ & 18 & 44.8 & 57.6 & & 14.7 & & $\mathrm{Y}$ & 10 & 40.4 & 66.7 & & 13.1 & \\
\hline \multirow[t]{2}{*}{ CCR5 BL } & $\mathrm{N}$ & 17 & 0.59 & 0.50 & 0.21 & 0.45 & 0.18 & $\mathrm{~N}$ & 24 & 0.54 & 0.43 & 0.55 & 0.46 & 0.24 \\
\hline & $\mathrm{Y}$ & 18 & 0.42 & 0.21 & & 0.41 & & $\mathrm{Y}$ & 10 & 0.45 & 0.26 & & 0.39 & \\
\hline \multirow[t]{2}{*}{ CCR5 day 21} & $\mathrm{~N}$ & 17 & 0.73 & 0.62 & 0.14 & 0.58 & 0.16 & $\mathrm{~N}$ & 24 & 0.71 & 0.53 & 0.066 & 0.55 & 0.008 \\
\hline & $\mathrm{Y}$ & 18 & 0.48 & 0.23 & & 0.45 & & $\mathrm{Y}$ & 10 & 0.38 & 0.13 & & 0.37 & \\
\hline \multirow[t]{2}{*}{ CCR5 PD } & $\mathrm{N}$ & 17 & 0.74 & 0.82 & 0.18 & 0.68 & 0.58 & $\mathrm{~N}$ & 24 & 0.65 & 0.72 & 0.45 & 0.49 & 0.68 \\
\hline & $\mathrm{Y}$ & 18 & 0.45 & 0.26 & & 0.44 & & $\mathrm{Y}$ & 10 & 0.47 & 0.28 & & 0.40 & \\
\hline
\end{tabular}

BL, Baseline; PD, progressive disease; DC, disease control; TS, tumor shrinkage; SD, standard deviation; N, no; Y, yes. *Differences in the mean and median serum factor levels were tested using Student's unpaired $t$-test and Mann-Whitney $U$-test, respectively. $p$-Values $<0.05$ are shown in bold.

Table V. Correlations among serum factors.

\begin{tabular}{lccccccccccc}
\hline Pairs of factors & $\begin{array}{c}\text { CCL3- } \\
\text { CCL4 }\end{array}$ & $\begin{array}{c}\text { CCL3- } \\
\text { CCL5 }\end{array}$ & $\begin{array}{c}\text { CCL3- } \\
\text { CCR5 }\end{array}$ & $\begin{array}{c}\text { CCL4 } \\
\text { CCL5 }\end{array}$ & $\begin{array}{c}\text { CCL4- } \\
\text { CCR5 }\end{array}$ & $\begin{array}{c}\text { CCL5- } \\
\text { CCR5 }\end{array}$ & $\begin{array}{c}\text { CCL3- } \\
\text { VEGF }\end{array}$ & $\begin{array}{c}\text { CCL4- } \\
\text { VEGF }\end{array}$ & $\begin{array}{c}\text { CCL5- } \\
\text { VEGF }\end{array}$ & $\begin{array}{c}\text { CCR5- } \\
\text { VEGF }\end{array}$ \\
\hline Points & & & & & & & & & & & \\
BL & $\varrho=-0.242$ & $\varrho=-0.069$ & $\varrho=0.084$ & $\varrho=0.133$ & $\varrho=-0.135$ & $\varrho=0.275$ & $\varrho=-0.048$ & $\varrho=-0.133$ & $\varrho=0.033$ & $\varrho=-0.118$ \\
Day 21 & $\varrho=-0.124$ & $\varrho=-0.337^{*}$ & $\varrho=0.168$ & $\varrho=0.351^{*}$ & $\varrho=0.107$ & $\varrho=0.191$ & $\varrho=-0.088$ & $\varrho=0.241$ & $\varrho=0.238$ & $\varrho=-0.035$ \\
PD & $\varrho=0.117$ & $\varrho=0.058$ & $\varrho=-0.025$ & $\varrho=0.352$ & $\varrho=0.411^{*}$ & $\varrho=-0.131$ & $\varrho=0.146$ & $\varrho=0.381^{*}$ & $\varrho=0.373 *$ & $\varrho=0.077$ \\
Changes & & & & & & & & & & & \\
BL-day21 & $\varrho=-0.260$ & $\varrho=0.029$ & $\varrho=0.220$ & $\varrho=-0.205$ & $\mathrm{r}=-0.171$ & $\varrho=0.065$ & $\varrho=0.010$ & $\varrho=-0.017$ & $\varrho=0.163$ & $\varrho=0.262$ \\
BL-PD & $\varrho=0.153$ & $\varrho=0.377^{*}$ & $\varrho=0.105$ & $\varrho=0.039$ & $\varrho=0.011$ & $\varrho=-0.068$ & $\varrho=-0.167$ & $\varrho=-0.013$ & $\varrho=0.105$ & $\varrho=0.111$ \\
\hline
\end{tabular}

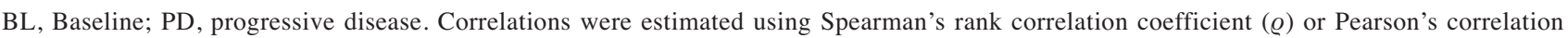
coefficient (r) according to data distribution. $* p$-Values are $<0.05$.

and CCL4 rs1634517 C/C variant $(r=-0.475, p=0.034)$, whereas no correlation was observed in any A allele in either $C C L 3$ or $C C L 4$ SNPs $(\varrho=-0.173, p=0.492 ; \varrho=-0.099$, $p=0.736$ ). In addition, $C C L 5$ SNPs showed no significant correlation between CCL3 and CCL4.

\section{Discussion}

In this study, we aimed to evaluate the CCL3, CCL4, CCL5, and CCR5 network more comprehensively by further analyzing serum CCL3, CCL4, and CCR5 levels in addition to CCL5 and VEGF-A. We demonstrate the candidate biological role of $C C L 3$ and CCL4 SNPs, based on the analysis of circulating protein levels in mCRC patients receiving regorafenib.

The CCL5/CCR5 axis is involved in the immune microenvironment and promotes tumor progression $(12,13)$. CCL 3 and CCL4 are produced particularly by macrophages, dendritic cells, and lymphocytes that activate CCR5 downstream $(14,15)$. In a gene expression analysis study for colorectal cancer, CCL4 was the most strongly expressed in cancer tissues compared to those expressed in non-neoplastic mucosal tissues. CCL3 was also highly expressed in cancer tissues. In contrast, CCL5 was widely expressed not only in 
Table VI. Associations between SNPs and serum factor levels.

\begin{tabular}{|c|c|c|c|c|c|c|c|c|c|c|c|c|c|}
\hline \multirow[b]{2}{*}{ SNP } & \multirow[b]{2}{*}{ Variant } & \multicolumn{4}{|c|}{ Median CCL3 levels (pg/ml) } & \multicolumn{4}{|c|}{ Median CCL4 levels (pg/ml) } & \multicolumn{4}{|c|}{ Median CCR5 levels (pg/ml) } \\
\hline & & BL & $\begin{array}{l}\text { Day } \\
21\end{array}$ & $\begin{array}{c}\text { BL-day } \\
21\end{array}$ & $\begin{array}{l}\text { INC } \\
(\%)^{*}\end{array}$ & BL & $\begin{array}{l}\text { Day } \\
21\end{array}$ & $\begin{array}{c}\text { BL-day } \\
21\end{array}$ & $\begin{array}{l}\text { INC } \\
(\%)^{*}\end{array}$ & $\mathrm{BL}$ & $\begin{array}{c}\text { Day } \\
21\end{array}$ & $\begin{array}{c}\text { BL-day } \\
21\end{array}$ & $\begin{array}{l}\text { INC } \\
(\%)^{*}\end{array}$ \\
\hline \multirow[t]{2}{*}{ CCL3 rs1130371 } & $\mathrm{G} / \mathrm{G}$ & 16.7 & 30.1 & 9.5 & 70.6 & 67.7 & 48.4 & -17.5 & 41.2 & 0.40 & 0.49 & 0.17 & 64.7 \\
\hline & Any A & 22.9 & 20.8 & -4.6 & 38.9 & 35.3 & 26.7 & 2.2 & 50.0 & 0.47 & 0.40 & 0.03 & 55.6 \\
\hline$p$-Value & & 0.27 & 0.49 & 0.041 & 0.092 & 0.077 & 0.060 & 0.43 & 0.74 & 0.41 & 0.14 & 0.083 & 0.73 \\
\hline \multirow[t]{2}{*}{ CCL4 rs1634517 } & $\mathrm{C} / \mathrm{C}$ & 20.8 & 30.1 & 5.6 & 57.1 & 39.4 & 35.5 & -8.8 & 42.9 & 0.48 & 0.49 & 0.17 & 71.4 \\
\hline & Any A & 19.2 & 20.7 & -0.12 & 50.0 & 44.1 & 26.9 & 1.0 & 50.0 & 0.40 & 0.40 & -0.035 & 42.9 \\
\hline$p$-Value & & 0.74 & 0.27 & 0.14 & 0.74 & 0.61 & 0.45 & 0.53 & 0.74 & 0.35 & 0.12 & 0.042 & 0.16 \\
\hline \multirow[t]{2}{*}{ CCL5 rs2280789 } & $\mathrm{A} / \mathrm{A}$ & 22.9 & 20.8 & -7.1 & 23.1 & 34.2 & 43.8 & 12.9 & 69.2 & 0.45 & 0.45 & 0.12 & 69.2 \\
\hline & Any G & 16.4 & 31.1 & 7.81 & 72.7 & 59.1 & 27.8 & -19.7 & 31.8 & 0.42 & 0.45 & 0.03 & 54.5 \\
\hline$p$-Value & & 0.097 & 0.35 & 0.034 & 0.006 & 0.15 & 0.53 & 0.017 & 0.043 & 0.99 & 0.67 & 0.57 & 0.49 \\
\hline \multirow[t]{2}{*}{ CCL5 rs3817655 } & $\mathrm{A} / \mathrm{A}$ & 22.88 & 20.83 & -7.11 & 23.1 & 34.24 & 43.82 & 12.88 & 69.2 & 0.45 & 0.45 & 0.12 & 69.2 \\
\hline & Any $\mathrm{T}$ & 16.4 & 31.1 & 7.81 & 72.7 & 59.1 & 27.8 & -19.7 & 31.8 & 0.42 & 0.45 & 0.025 & 54.5 \\
\hline$p$-Value & & 0.097 & 0.35 & 0.034 & 0.006 & 0.15 & 0.53 & 0.017 & 0.043 & 0.99 & 0.67 & 0.57 & 0.49 \\
\hline \multirow[t]{2}{*}{ CCR5 rs1799988 } & Any $\mathrm{C}$ & 20.8 & 20.8 & 1.62 & 52.0 & 44.1 & 35.1 & -4.4 & 48.0 & 0.43 & 0.45 & 0.03 & 60.0 \\
\hline & $\mathrm{T} / \mathrm{T}$ & 22.7 & 26.4 & 7.5 & 60.0 & 37.47 & 17.5 & -4.4 & 40.0 & 0.44 & 0.59 & 0.085 & 60.0 \\
\hline$p$-Value & & 0.83 & 0.61 & 0.47 & 0.72 & 0.69 & 0.19 & 0.93 & 0.72 & 0.84 & 0.16 & 0.58 & 1.0 \\
\hline
\end{tabular}

BL, Baseline; PD, progressive disease; INC, increased. *Increased at day 21 from BL. $p$-Values $<0.05$ are shown in bold. Differences in the median serum factor levels were tested using Mann-Whitney $U$-test.

cancer tissue but also in non-neoplastic mucosal tissues (9) and was reported to play an important role in activating CCL5 signaling via CCR5 $(7,16,17)$.

In the analysis of serum factor levels in our study, we could confirm the relationship between different CCL3 and CCL4 changes and efficacy after the administration of regorafenib. Furthermore, we examined the changes in serum factors for each SNP variant, and the CCL3 rs1130371 G/G and CCL4 rs1634571 C/C variants were associated with longer PFS and OS. CCL3 and CCL4 are known to be specifically expressed in cancer tissue, but lack the ability to induce EPC migration. In contrast, CCL5 expression is not limited to cancer tissue and induces EPC migration where CCR5 and the ligands are expressed $(8,9)$. In this study, serum CCL3 levels increased in the $\mathrm{G} / \mathrm{G}$ variant of CCL3 rs 1130371, which suggests that the $G / G$ variant serves as a prognostic factor. For CCL4, there was no significant correlation between serum levels and the SNP. The most interesting finding was the additional analysis of CCL5 SNPs, which has been previously reported to be associated with serum CCL5 and VEGF-A levels (10). Namely, an increase in serum CCL3 and a decrease in CCL4 after regorafenib administration were observed only in theCCL5 rs2280789 G/G variant and CCL5 rs3817655 T/T variant, suggesting that these genotypes may be prognostic factors.

Concerning drug-related toxicities, we had previously revealed that CCL5 SNPs act as prognostic markers of severe hand-foot skin reaction (HFSR), based on the capacity of VEGF-A production, which is an important factor in wound healing $(18,19)$. In this study, there was no significant correlation between CCL3, CCL4, CCR5 and HFSR. Therefore, CCL5-CCR5-VEGF-A signaling seems to play an important role in the development of severe HFSR in the CCR5 network. Thus, given that most CCL5 is derived from the host $(20,21)$, CCL5 genotyping remains a predictor of severe HFSR due to regorafenib.

Our findings can be summarized in three key points: (i) Both increased CCL3 and decreased CCL4 appear to be involved in antitumor effects; (ii) The prognostic value of CCL3 and CCL4 SNPs shown in our previous study (10) depends on the variation in CCL3 and CCL4 responses to regorafenib; that is, negative correlations between CCL3 and CCL4 were observed in both the CCL3 rs1130371 G/G variant and CCL4 rs1634517 C/C variant; and (iii) CCL5 SNPs may impact the opposing reactions of CCL3 and CCL4. However, our study has some limitations: the retrospective study design, lack of preclinical data regarding the function of SNPs and limited number of serum factors testing and samples. In contrast, we demonstrated the relationship between serum factor levels and SNPs in CCL5/CCR5 network more systematically in patients receiving regorafenib, and the mechanism should be clarified through further research.

In conclusion, both increased CCL3 and decreased CCL4 are considered to be one of the mechanisms of action of regorafenib efficacy, and differences between CCL3 and CCL4 changes were found in a specific genotype of CCL5 SNPs. This suggests an alternative mechanism of action in 
the CCR5 network besides CCL5-VEGF-A signaling via EPC in mCRC patients receiving regorafenib. Furthermore, $C C L 3$ and CCL4 SNPs remain prognostic markers for the efficacy of regorafenib. Development of new therapeutic targeting molecules in this network is expected in the future.

\section{Conflicts of Interest}

The Authors have no conflicts of interest to declare in this work.

\section{Authors' Contributions}

Conceptualization: MS (Mitsukuni Suenaga), WZ, TM, HL. Data curation: MS (Mitsukuni Suenaga), TM. Formal analysis: SC. Funding acquisition: MS (Mitsukuni Suenaga), HL. Investigation: MS (Mitsukuni Suenaga), WZ. Methodology: MS (Mitsukuni Suenaga), WZ, TM. Project administration: MS (Marta Schirripa), SO, MB, YM. Resources: MS (Mitsukuni Suenaga), WZ, TY. Software: SC, AB. Supervision: HL. Writing-original draft: MS (Mitsukuni Suenaga). Writing-review and editing: All Authors.

\section{Acknowledgements}

Mitsukuni Suenaga is the recipient of Takashi Tsuruo Memorial Fund and Martin D. Berger received a grant from the Swiss Cancer League (BIL KLS-3334-02-2014) and the Werner and Hedy Berger-Janser Foundation for cancer research. Yuji Miyamoto received a grant from Japan Society for the Promotion of Science (S2606). This work was partially supported by the National Cancer Institute (P30CA01408927S1), the Gloria Borges Wunderglo Project, the Dhont Family Foundation, the Dave Butler Research Fund, the Call to Cure Research Fund, and JSPS KAKENHI Grant Number 18K07280.

\section{References}

1 Grothey A, Van Cutsem E, Sobrero A, Siena S, Falcone A, Ychou M, Humblet Y, Bouché O, Mineur L, Barone C, Adenis A, Tabernero J, Yoshino T, Lenz HJ, Goldberg RM, Sargent DJ, Cihon F, Cupit L, Wagner A, Laurent D and CORRECT study group: Regorafenib monotherapy for previously treated metastatic colorectal cancer (CORRECT): An international, multicentre, randomised, placebo-controlled, phase 3 trial. Lancet 381(9863): 303-312, 2013. PMID: 23177514. DOI: 10.1016/S0140-6736(12)61900-X

2 Li J, Qin S, Xu R, Yau TC, Ma B, Pan H, Xu J, Bai Y, Chi Y, Wang L, Yeh KH, Bi F, Cheng Y, Le AT, Lin JK, Liu T, Ma D, Kappeler C, Kalmus J, Kim TW and CONCUR Investigators: Regorafenib plus best supportive care versus placebo plus best supportive care in Asian patients with previously treated metastatic colorectal cancer (CONCUR): A randomised, double-blind, placebo-controlled, phase 3 trial. Lancet Oncol 16(6): 619-629, 2015. PMID: 25981818. DOI: 10.1016/S1470-2045(15)70156-7

3 Tabernero J, Lenz HJ, Siena S, Sobrero A, Falcone A, Ychou M, Humblet Y, Bouché O, Mineur L, Barone C, Adenis A, Yoshino T, Goldberg RM, Sargent DJ, Wagner A, Laurent D, Teufel M, Jeffers M, Grothey A and Van Cutsem E: Analysis of circulating DNA and protein biomarkers to predict the clinical activity of regorafenib and assess prognosis in patients with metastatic colorectal cancer: A retrospective, exploratory analysis of the CORRECT trial. Lancet Oncol 16(8): 937-948, 2015. PMID: 26184520. DOI: 10.1016/S1470-2045(15)00138-2

4 Suenaga M, Mashima T, Kawata N, Wakatsuki T, Horiike Y, Matsusaka S, Dan S, Shinozaki E, Seimiya H, Mizunuma N, Yamaguchi K and Yamaguchi T: Serum VEGF-A and CCL5 levels as candidate biomarkers for efficacy and toxicity of regorafenib in patients with metastatic colorectal cancer. Oncotarget 7(23): 34811-34823, 2016. PMID: 27166185. DOI: 10.18632/oncotarget.9187

5 Song A, Nikolcheva $\mathrm{T}$ and Krensky AM: Transcriptional regulation of RANTES expression in T lymphocytes. Immunol Rev 177: 236-245, 2000. PMID: 11138780. DOI: 10.1034/j.1600-065x.2000.17610.x

6 Song A, Patel A, Thamatrakoln K, Liu C, Feng D, Clayberger C and Krensky AM: Functional domains and DNA-binding sequences of RFLAT-1/KLF13, a Krüppel-like transcription factor of activated T lymphocytes. J Biol Chem 277(33): 3005530065, 2002. PMID: 12050170. DOI: 10.1074/jbc.M204278200

7 Wang SW, Liu SC, Sun HL, Huang TY, Chan CH, Yang CY, Yeh HI, Huang YL, Chou WY, Lin YM and Tang CH: CCL5/CCR5 axis induces vascular endothelial growth factor-mediated tumor angiogenesis in human osteosarcoma microenvironment. Carcinogenesis 36(1): 104-114, 2015. PMID: 25330803. DOI: $10.1093 /$ carcin/bgu218

8 Ishida Y, Kimura A, Kuninaka Y, Inui M, Matsushima K, Mukaida N and Kondo T: Pivotal role of the CCL5/CCR5 interaction for recruitment of endothelial progenitor cells in mouse wound healing. J Clin Invest 122(2): 711-721, 2012. PMID: 22214846. DOI: 10.1172/JCI43027

9 Musha H, Ohtani H, Mizoi T, Kinouchi M, Nakayama T, Shiiba K, Miyagawa K, Nagura H, Yoshie O and Sasaki I: Selective infiltration of CCR5(+)CXCR3(+) T lymphocytes in human colorectal carcinoma. Int J Cancer 116(6): 949-956, 2005. PMID: 15856455. DOI: 10.1002/ijc.21135

10 Suenaga M, Schirripa M, Cao S, Zhang W, Yang D, Ning Y, Cremolini C, Antoniotti C, Borelli B, Mashima T, Okazaki S, Berger MD, Miyamoto Y, Gopez R Jr, Barzi A, Lonardi S, Yamaguchi T, Falcone A, Loupakis F and Lenz HJ: Gene polymorphisms in the CCL5/CCR5 pathway as a genetic biomarker for outcome and hand-foot skin reaction in metastatic colorectal cancer patients treated with regorafenib. Clin Colorectal Cancer 17(2): e395-e414, 2018. PMID: 29606345. DOI: $10.1016 /$ j.clcc.2018.02.010

11 Lee PH and Shatkay H: F-SNP: Computationally predicted functional SNPs for disease association studies. Nucleic Acids Res 36(Database issue): D820-D824, 2008. PMID: 17986460. DOI: $10.1093 / \mathrm{nar} / \mathrm{gkm} 904$

12 Balkwill F: Cancer and the chemokine network. Nat Rev Cancer 4(7): 540-550, 2004. PMID: 15229479. DOI: 10.1038/nrc1388

13 Fridman WH, Pagès F, Sautès-Fridman C and Galon J: The immune contexture in human tumours: impact on clinical outcome. Nat Rev Cancer 12(4): 298-306, 2012. PMID: 22419253. DOI: $10.1038 / \mathrm{nrc} 3245$

14 Schlecker E, Stojanovic A, Eisen C, Quack C, Falk CS, Umansky $\mathrm{V}$ and Cerwenka A: Tumor-infiltrating monocytic myeloid-derived suppressor cells mediate CCR5-dependent recruitment of regulatory $\mathrm{T}$ cells favoring tumor growth. $\mathrm{J}$ Immunol 189(12): 5602-5611, 2012. PMID: 23152559. DOI: $10.4049 /$ jimmunol.1201018 
15 De la Fuente López M, Landskron G, Parada D, DuboisCamacho K, Simian D, Martinez M, Romero D, Roa JC, Chahuán I, Gutiérrez R, Lopez-K F, Alvarez K, Kronberg U, López S, Sanguinetti A, Moreno N, Abedrapo M, González MJ, Quera R and Hermoso-R MA: The relationship between chemokines CCL2, CCL3, and CCL4 with the tumor microenvironment and tumor-associated macrophage markers in colorectal cancer. Tumour Biol 40(11): 1010428318810059, 2018. PMID: 30419802. DOI: 10.1177/1010428318810059

16 Liu GT, Huang YL, Tzeng HE, Tsai CH, Wang SW and Tang $\mathrm{CH}$ : CCL5 promotes vascular endothelial growth factor expression and induces angiogenesis by down-regulating miR199a in human chondrosarcoma cells. Cancer Lett 357(2): 476487, 2015. PMID: 25444917. DOI: 10.1016/j.canlet.2014.11.015

17 Chang LY, Lin YC, Mahalingam J, Huang CT, Chen TW, Kang CW, Peng HM, Chu YY, Chiang JM, Dutta A, Day YJ, Chen TC, Yeh CT and Lin CY: Tumor-derived chemokine CCL5 enhances TGF- $\beta$-mediated killing of CD8(+) T cells in colon cancer by Tregulatory cells. Cancer Res 72(5): 1092-1102, 2012. PMID: 22282655. DOI: 10.1158/0008-5472.CAN-11-2493

18 Lacouture ME, Reilly LM, Gerami P and Guitart J: Hand foot skin reaction in cancer patients treated with the multikinase inhibitors sorafenib and sunitinib. Ann Oncol 19(11): 1955-1961, 2008. PMID: 18550575. DOI: 10.1093/annonc/mdn389
19 Xie H, Lafky JM, Morlan BW, Stella PJ, Dakhil SR, Gross GG, Loui WS, Hubbard JM, Alberts SR and Grothey A: Dual VEGF inhibition with sorafenib and bevacizumab as salvage therapy in metastatic colorectal cancer: Results of the phase II north central cancer treatment group study N054C (alliance). Ther Adv Med Oncol 12: 1758835920910913, 2020. PMID: 32201506. DOI: $10.1177 / 1758835920910913$

20 Zhang Y, Lv D, Kim HJ, Kurt RA, Bu W, Li Y and Ma X: A novel role of hematopoietic CCL5 in promoting triple-negative mammary tumor progression by regulating generation of myeloid-derived suppressor cells. Cell Res 23(3): 394-408, 2013. PMID: 23266888. DOI: 10.1038/cr.2012.178

21 Jayasinghe MM, Golden JM, Nair P, O’Donnell CM, Werner MT and Kurt RA: Tumor-derived CCL5 does not contribute to breast cancer progression. Breast Cancer Res Treat 111(3): 511-521, 2008. PMID: 17978871. DOI: 10.1007/s10549-007-9802-6

Received February 26, 2021

Revised March 11, 2021

Accepted March 12, 2021 